\title{
Lead Telluride $p$ - $n$ Junctions for Infrared Detection: Electrical and Optical Characteristics
}

\author{
A. S. Barros, E. Abramof, and P. H. O. Rappl \\ Laboratório Associado de Sensores e Materiais, Instituto Nacional de Pesquisas Espaciais, \\ Caixa Postal 515, 12245-970 São José dos Campos-SP, Brazil
}

Received on 4 April, 2005

\begin{abstract}
PbTe mesa diodes were fabricated from a series of $p-n$ junctions grown on $\mathrm{BaF}_{2}$ substrates. For this series, the hole concentration was kept constant at $10^{17} \mathrm{~cm}^{-3}$ and the electron concentration varied between $10^{17}$ and $10^{19} \mathrm{~cm}^{-3}$. Capacitance versus voltage analysis revealed that for $n>10^{18} \mathrm{~cm}^{-3}$, a one-sided abrupt junction is formed. The direct and reverse branches of the current versus voltage curves exhibited different forms among the diodes. The $\mathrm{R}_{0} \mathrm{~A}$ product varied between 0.23 and $31.8 \Omega \mathrm{cm}^{2}$, and the integral detectivity ranged from $1.1 \times 10^{8}$ to $6.5 \times 10^{10} \mathrm{cmHz}^{1 / 2} \mathrm{~W}^{-1}$. The performance of the best PbTe photodiodes fabricated here is comparable to the commercial InSb and $\mathrm{HgCdTe}$ infrared detectors, and to the PbTe sensors grown on Si substrate.
\end{abstract}

Keywords: Infrared detection; Electrical and optical characteristics; PbTe mesa diodes

\section{INTRODUCTION}

Due to its energy gap of $190 \mathrm{meV}$ at $77 \mathrm{~K}$, lead telluride is a good candidate material for detection applications in the mid-wavelength infrared region. PbTe photovoltaic infrared sensors can be either of the Schottky barrier [1] or of $p-n$ junction types [2,3]. The photodiodes are normally made from $\mathrm{PbTe}$ layers grown on $\mathrm{BaF}_{2}$ substrates or on $\mathrm{Si}$ substrates using fluoride buffer layers. With device performance comparable to the metal Schottky barriers, PbTe $p-n$ junctions have recently attracted attention as infrared sensors [3-5]. It is well known that the electrical characteristics of the $p-n$ junction strongly influence the detector performance.

In this work, we decided to investigate the electrical and optical characteristics of $\mathrm{PbTe} p-n$ junctions as a function of the carrier concentration of the constituent layers. For this purpose, we grew a series of PbTe $p-n$ junctions by molecular beam epitaxy (MBE) on (111) $\mathrm{BaF}_{2}$ substrates. For this series, the hole concentration of the PbTe $p$-layer was kept constant at $10^{17} \mathrm{~cm}^{-3}$ and the electron concentration of the $n$-type layer was varied between $10^{17}$ and $10^{19} \mathrm{~cm}^{-3}$. Mesa diodes were fabricated by lithography process and assembled in a $\mathrm{LN}_{2}$ cryostat for characterization.

Capacitance versus voltage $(\mathrm{CxV})$ and current versus voltage $(\mathrm{IxV})$ characteristic curves were measured for diodes produced from the different $p-n$ junctions. We also measured the integral detectivity and spectral response, in an infrared optical bench. It was possible to correlate the device's figures of merit to the data obtained from the electrical characterization.

\section{DEVICE FABRICATION}

All samples were grown in a Riber 32P MBE apparatus equipped with effusion cells containing $\mathrm{PbTe}, \mathrm{Te}$ and $\mathrm{Bi}_{2} \mathrm{Te}_{3}$ solid sources. Before properly growing the $p-n$ junctions, $\mathrm{PbTe}$ reference layers were grown on $\mathrm{BaF}_{2}$ substrates in order to determine the best MBE growth parameters to obtain both types of conduction. The resistivity, type and carrier concentration, and mobility of the reference layers were measured at 300 and $77 \mathrm{~K}$ in a Hall Effect system in automatic data acquisition mode with an electromagnet field of 0.7 Tesla.

Since the deviation from stoichiometry plays an important role in the carrier character of the lead salts, our MBE $\mathrm{Pb}_{1-y} \mathrm{Te}_{y}$ solid source is intentionally prepared metal rich $(y=0.495)$. Using this source, an $n$-type PbTe layer with an electron concentration of about $5 \times 10^{16} \mathrm{~cm}^{-3}$ is normally grown at the usual substrate temperature of $30^{\circ} \mathrm{C}$ without additional Te flux. In order to obtain the $p$-type layer, the additional Te flux is increased until the character transition from $n$ to $p$ occurs, as shown in Fig. 1. An extra Te flux of about $8 \times 10^{-9}$ Torr is necessary in these conditions to change the carrier type.

By playing with the stoichiometry in the MBE system, both $p$ and $n$-type PbTe layers with carrier concentration in the range of $10^{17} \mathrm{~cm}^{-3}$ could be obtained. To achieve higher electron concentration, the PbTe layers must be doped extrinsically. Bismuth, through the $\mathrm{Bi}_{2} \mathrm{Te}_{3}$ effusion cell, is normally used as an $n$-type dopant. A detailed study of Bi doping of $\mathrm{PbTe}$ layers in our MBE system was previously done [6]. Using this work as a reference, we have determined the $\mathrm{Bi}_{2} \mathrm{Te}_{3}$ flux necessary to grow PbTe layers with the desired electron concentration of $10^{17}, 10^{18}$ and $10^{19} \mathrm{~cm}^{-3}$.

After this calibration procedure, a series of $p-n$ junction samples were produced. To form the junctions, a $5 \mu \mathrm{m}$ thick $p$-type layer is firstly grown on top of $\mathrm{a} \mathrm{BaF}_{2}$ substrate followed by an $n$-type layer of approximately $2 \mu \mathrm{m}$. For identification, the junctions with electron concentration in order of $10^{17}, 10^{18}$ and $10^{19} \mathrm{~cm}^{-3}$ were named $p-n, p-n^{+}$and $p-n^{++}$, respectively.

Mesa structures were fabricated by lithography process. A stainless steel mask with circular holes with diameters of 1.0 and $0.3 \mathrm{~mm}$ was used to deposit Au discs with $200 \mathrm{~nm}$ of thickness on top of the $n$-type layer. An electron beam source was used to evaporate gold and a quartz crystal monitor controlled the film thickness. These discs were used as protective masks for the etching process as well as metallic contacts. Mesas were etched using a solution of $\mathrm{Br}_{2}: \mathrm{HBr}_{2} \mathrm{H}_{2} \mathrm{O}$ 


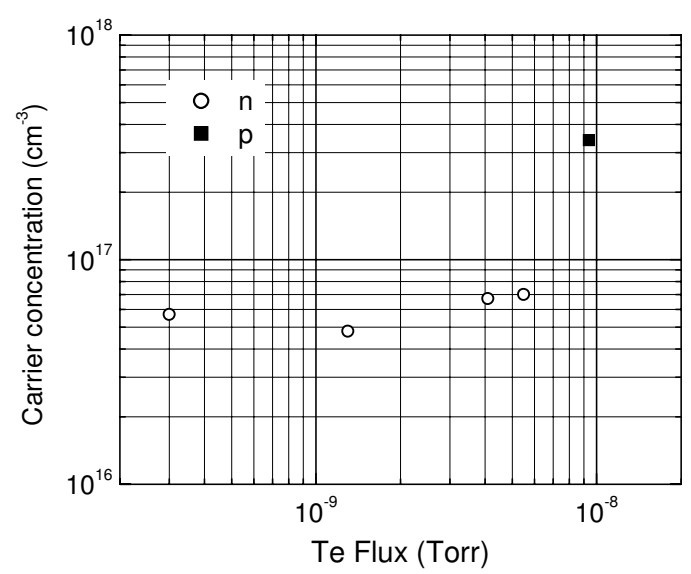

FIG. 1: Carrier concentration at $77 \mathrm{~K}$ versus additional Te flux for the $\mathrm{PbTe}$ layers grown at $300^{\circ} \mathrm{C}$. The transition of character $n$ to $p$ occurs at about $8 \times 10^{-9}$ Torr.

(1:40:40) until the $p$-type layer is reached. Another stainless steel mask was used to deposit Au pads involving each mesa structure to form the diode. Each $15 \times 15 \mathrm{~mm}^{2} \mathrm{BaF}_{2}$ wafer contain nine diodes with the two different mesa diameters. Gold wires were soldered to both Au pads with indium. The diode was mounted on a $\mathrm{Cu}$ plate and assembled in a $\mathrm{LN}_{2}$ cryostat.

\section{C $\times$ V CHARACTERISTICS}

The capacitance versus voltage characteristic of the produced diodes was measured with a HP4280A capacitance meter. The capacitance is measured through an alternate signal of 10 or $30 \mathrm{mV}$ in a frequency of $1 \mathrm{MHz}$ applied together with the DC voltage. The maximum capacitance measurable in this equipment is $2 \mathrm{nF}$. Due to the high dielectric constant of PbTe $(\kappa=800 @ 77 \mathrm{~K})$, the diodes with $0.3 \mathrm{~mm}$ of diameter were designed in order to not overpass this value.

The upper panel of Fig. 2 shows the $\mathrm{CxV}$ characteristic at $80 \mathrm{~K}$ of a diode fabricated from a $p-n$ PbTe junction ( $p$ and $n \sim 10^{17} \mathrm{~cm}^{-3}$ ), and the lower panel plots the inverse of square of the specific capacitance $\mathrm{C}_{e}$ (capacitance per unit area) as a function of the reverse voltage. The complete non linear behavior of the $1 / \mathrm{C}_{e}^{2} \mathrm{xV}$ curve, observed for this diode, indicates that the depletion region extends to both sides of the junction. In the other hand, for the $p-n^{+}$and $p-n^{++}$junctions, the $1 / \mathrm{C}_{e}^{2} \mathrm{xV}$ plot exhibited an almost linear behavior, as shown in the lower panel of Fig. 3. This result indicates that for electron concentration higher than $10^{18} \mathrm{~cm}^{-3}$, a onesided abrupt $\mathrm{PbTe}$ junction is formed with the depletion region located practically at the $p$ side. For this type of junction, the hole concentration can be determined by the slope of the $1 / \mathrm{C}_{e}^{2} \mathrm{xV}$ plot and the depletion width can be obtained from the $\mathrm{CxV}$ characteristic [5].

The hole concentration determined from the $\mathrm{CxV}$ characteristic of the diodes fabricated from the $p-n^{+}$junction was $1.1 \times 10^{17} \mathrm{~cm}^{-3}$, a value very close to $p=1.8 \times 10^{17} \mathrm{~cm}^{-3} \mathrm{ob}-$ tained for the reference layer by Hall Effect measurement.

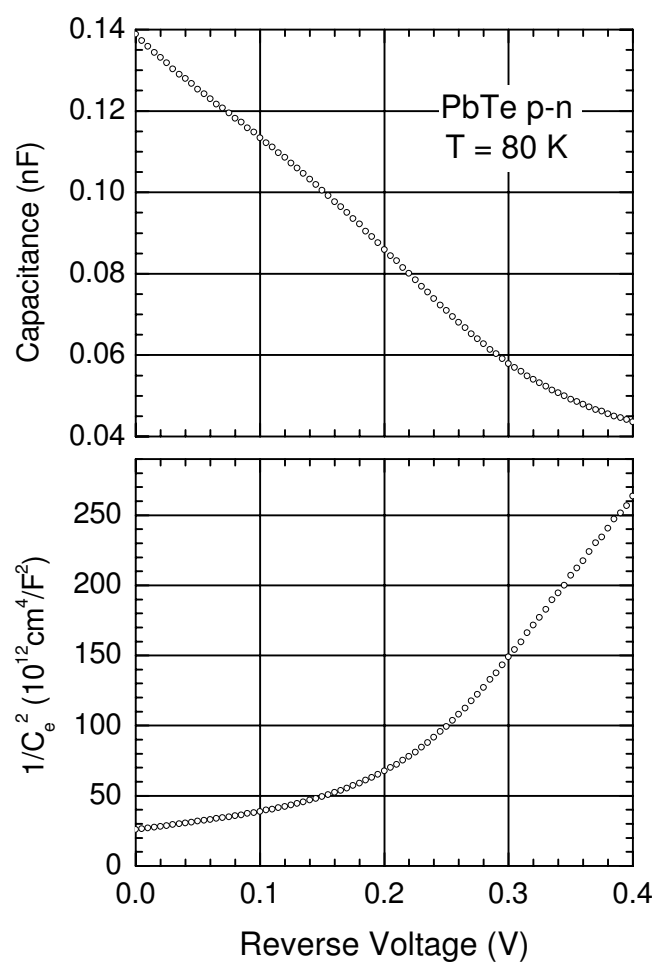

FIG. 2: $\mathrm{CxV}$ and $1 / \mathrm{C}_{e}^{2} \mathrm{xV}$ curves, where $\mathrm{C}_{e}$ is the capacitance per unit area, for a $p-n$ PbTe junction $\left(p=n \sim 10^{17} \mathrm{~cm}^{-3}\right)$.
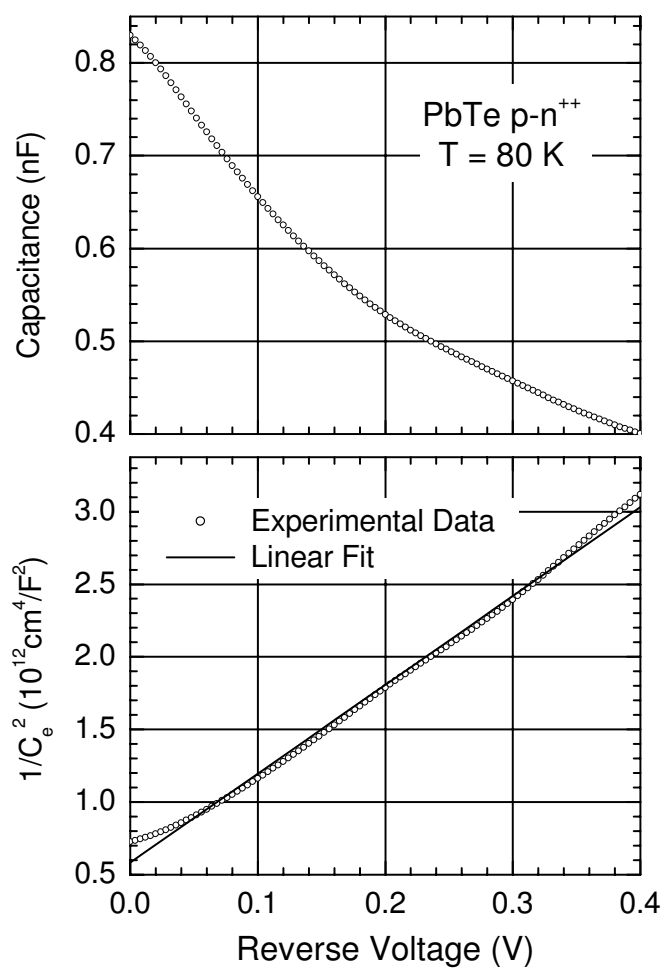

FIG. 3: $\mathrm{CxV}$ and $1 / \mathrm{C}_{e}^{2} \mathrm{xV}$ plots for a $p-n^{++}$PbTe junction $\left(p=10^{17}\right.$ and $n=10^{19} \mathrm{~cm}^{-3}$ ). 
In case of diodes from the $p-n^{++}$junctions, a lower value of hole concentration at about $3 \times 10^{16} \mathrm{~cm}^{-3}$ was determined from the slope of the $1 / \mathrm{C}_{e}^{2} \mathrm{xV}$ plot (Fig. 3). This fact indicate that bismuth inter-diffusion may start to take place for $\mathrm{PbTe}$ junctions with electron concentration as high as $10^{19} \mathrm{~cm}^{-3}$. The depletion width for the $p-n^{+}$and $p-n^{++}$junctions at $\mathrm{V}=0$ were close to $1 \mu \mathrm{m}$. This value agrees with published data for $\mathrm{PbTe} p-n^{+}$diodes grown on Si substrates [3].

\section{IXV CHARACTERISTICS}

The current versus voltage characteristics of all diodes were measured in a self-assembled automatic system composed of a programmable power supply, an ammeter and a voltmeter [5]. Fig. 4 shows, as an example, the IxV curve for a PbTe diode fabricated from $p-n^{++}$junction. In this case, the diode presented a nice IxV characteristic with a low leakage current in the reverse branch and a small series resistance in the forward direction. The lower panel of Fig. 4 plots the inverse of the derivative of the IxV curve $(\delta \mathrm{V} / \delta \mathrm{I})$. This plot allows the determination of the incremental differential resistance $\left(\mathrm{R}_{0}\right)$ and the $R_{0} A$ product, where $A$ is the photodiode area.

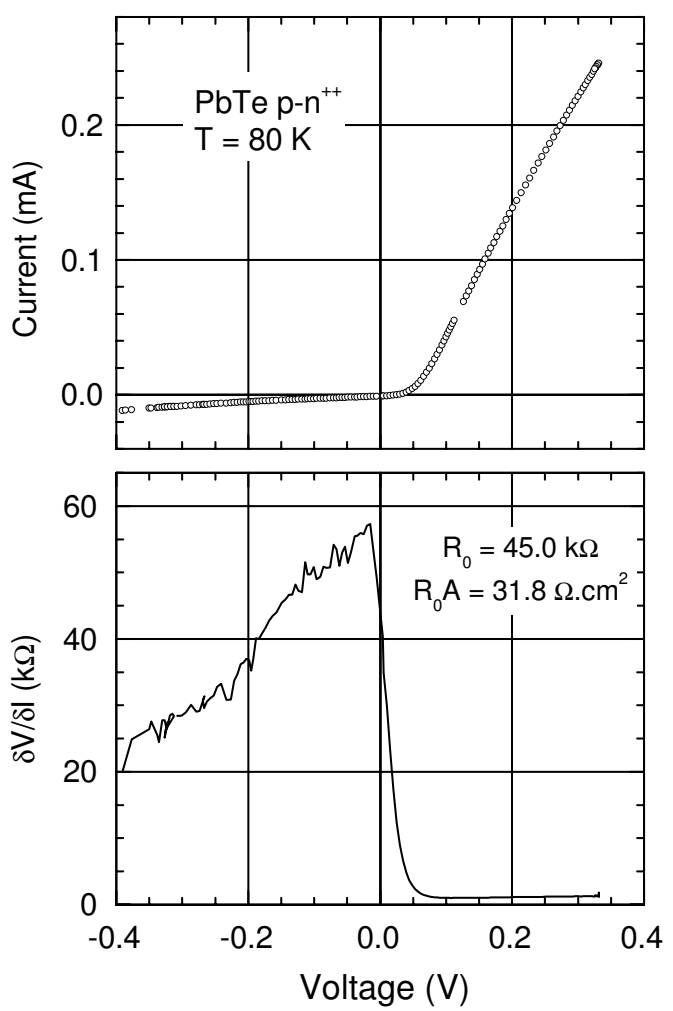

FIG. 4: IxV characteristic for a diode with a small leakage current fabricated from a $p-n^{++} \mathrm{PbTe}$ junction.

We have observed, contrarily to the $\mathrm{CxV}$ results, that the IxV curves exhibited different formats and values among all measured diodes. Even for diodes fabricated from the same junction, different shapes were observed for both direct and
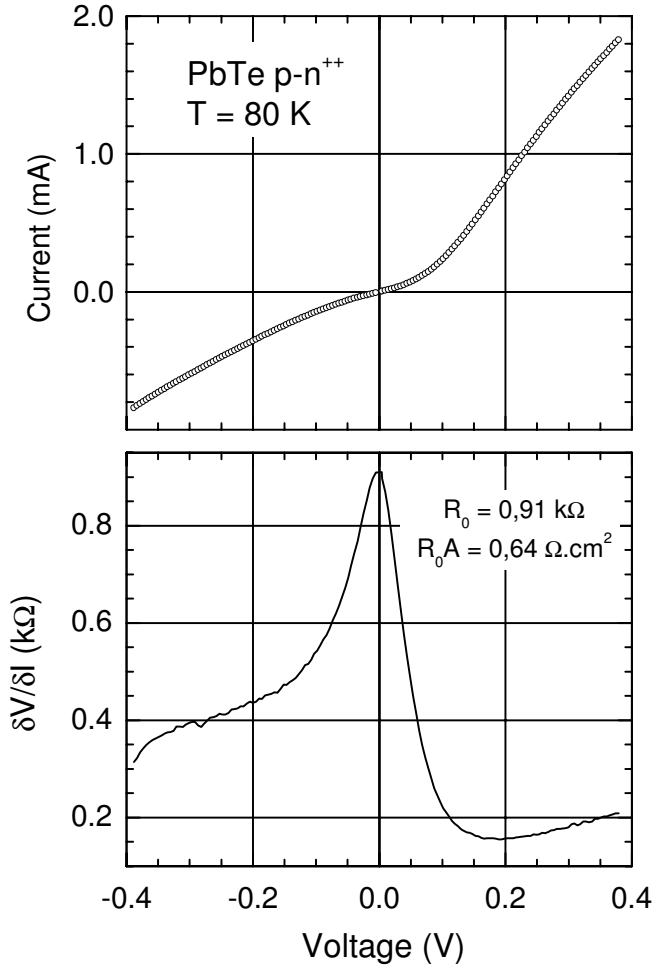

FIG. 5: IxV characteristic for a PbTe diode presenting a large leakage produced from a $p-n^{++}$junction.

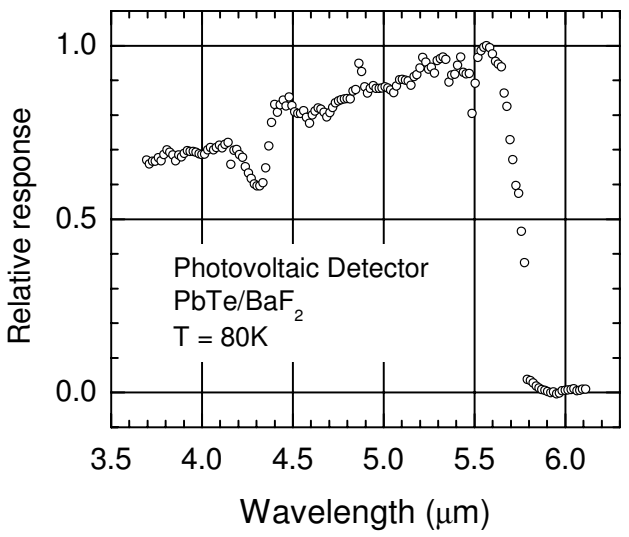

FIG. 6: Typical spectral response of PbTe photodiodes fabricated here.

reverse branches. The leakage current and the series resistance presented a significant variation among the diodes. Fig. 5 shows, as an illustration, the IxV curve of a diode, which exhibits a large leakage current, produced from a $p-n^{++}$junction.

The incremental differential resistance, determined for all diodes, varied between 0.32 and $45 \mathrm{k} \Omega$ and the $\mathrm{R}_{0} \mathrm{~A}$ product 
from 0.23 to $31.8 \Omega \mathrm{cm}^{2}$. Due to this variation, it was not possible to find any correlation between the parameters obtained from the IxV curves and the electron concentration in the $p-n$ junction. We believe that this large variation observed for the $\mathrm{IxV}$ curves in the different diodes is due to non-uniformities during the diode processing and the absence of a passivation layer.

\section{DETECTIVITY AND SPECTRAL RESPONSE}

The photodiodes' figures of merit, i.e. detectivity and spectral response, were characterized in an infrared optical bench. The integral detectivity $\mathrm{D}^{*}$ was measured for all $\mathrm{PbTe}$ photodiodes at $80 \mathrm{~K}$. The radiation from a blackbody source at $\mathrm{T}=$ $900 \mathrm{~K}$, chopped with a frequency of $900 \mathrm{~Hz}$, illuminates the detector through the $\mathrm{BaF}_{2}$ window of the cryostat. A power density of $5.65 \times 10^{-4} \mathrm{Wcm}^{-2}$ reaches the detector and the root mean square voltage signal is measured in a lock-in amplifier with a bandwidth of $14 \mathrm{~Hz}$. The detector noise was measured for a background at $300 \mathrm{~K}$ and a field-of-view of $30^{\circ}$. The detectivity values of all measured photodiodes varied from $1.1 \times 10^{8}$ to $6.5 \times 10^{10} \mathrm{cmHz}^{1 / 2} \mathrm{~W}^{-1}$. Like the IxV curves, the detectivity also showed a large fluctuation among the different diodes. The detectivity $\mathrm{D}^{*}$ correlated well with the $\mathrm{R}_{0} \mathrm{~A}$ product. Diodes with the highest $\mathrm{R}_{0} \mathrm{~A}$ values exhibit the best performance in infrared detection, as expected.

The highest values of $\mathrm{R}_{0} \mathrm{~A}$ product, measured for the $\mathrm{PbTe}$ photodetectors grown on $\mathrm{BaF}_{2}$ substrates during this work, are close to the values found in the literature for $\mathrm{PbTe} p-n$ junction infrared sensor grown on $\mathrm{Si}$ substrates $[3,4]$. It is important to mention that the performance of the best PbTe photodiodes fabricated here with integral detectivity $\mathrm{D}^{*}$ of $6 \times 10^{10} \mathrm{cmHz}^{1 / 2} \mathrm{~W}^{-1}$ is comparable to commercial InSb and $\mathrm{HgCdTe}$ infrared detectors with cut-off wavelength around 6 $\mu \mathrm{m}$ that show peak detectivity $\mathrm{D}^{*}\left(\lambda_{\mathrm{p}}\right)$ in the range of $10^{11}$ $\mathrm{cmHz}^{1 / 2} \mathrm{~W}^{-1}$ at $77 \mathrm{~K}$ [7].

The spectral response was measured in the same system as for the detectivity, by placing a grating monochromator between the infrared source (Glowbar) and the detector. The spectral response of the infrared sensor under test is compared to the response of a piroeletctric reference detector. Fig. 6 shows a typical spectral response of the photodiode, which exhibits the cutoff wavelength of $5.9 \mu \mathrm{m}$, corresponding to the energy gap of PbTe. The drop in response observed at 4.3 $\mu \mathrm{m}$, in the region of $\mathrm{CO}_{2}$ absorption, is due to the difference in optical path for the measured photodiode and the piroelectric detector.

\section{CONCLUSION}

We have determined the electrical and optical properties of $\mathrm{PbTe}$ mesa diodes fabricated from $p-n$ junctions with different electron concentrations. The $\mathrm{CxV}$ analysis revealed a one-sided abrupt junction for $\mathrm{n}>10^{18} \mathrm{~cm}^{-3}$ with depletion widths around $1 \mu \mathrm{m}$. The $p$ concentration determined from the slope of $1 / \mathrm{C}_{e}^{2} \mathrm{xV}$ plot agreed with the one obtained from Hall measurements. The IxV curves exhibited different formats for both direct and reverse branches. The leakage current, the series resistance and the $\mathrm{D}^{*}$ values presented a significant variation among the different diodes. The detectivity correlated well with the $\mathrm{R}_{0} \mathrm{~A}$ product, and $\mathrm{D}^{*}$ values close to $10^{11} \mathrm{cmHz}^{1 / 2} \mathrm{~W}^{-1}$ were measured for the best photodiodes produced here.

\section{Acknowledgement}

We thank the partial support of FAPESP (Grant Nr. 00/12529-6) and CNPq (300811/04-7 and 302395/02-4).
[1] H. Zogg, A. Fach, C. Maissen, J. Masek, and S. Blunier, Optical Engineering 33, 1440 (1994).

[2] C. Boschetti, P.H.O Rappl, A.Y. Ueta, I.N. Bandeira, Infrared Phys. 34, 281 (1993).

[3] J. John and H. Zogg, J. Appl. Phys. 85, 3364 (1999).

[4] D. Zimin, K. Alchalabi, and H. Zogg, Physica E 13, 1220 (2002).
[5] A.S. Barros, E. Abramof, P.H.O. Rappl, A.Y. Ueta, and H. Closs, Braz. J. Phys. 34, 641 (2004).

[6] A.M.P. Anjos, E. Abramof, P.H.O. Rappl, A.Y. Ueta, and H. Closs, Braz. J. Phys. 34, 653 (2004).

[7] A. Rogaslki, Infrared Phys. \& Tech. 43, 187 (2002). 